\title{
Compound but non-linked heterozygous p.W14X and p.L279 V LPL gene mutations in a Chinese patient with long-term severe hypertriglyceridemia and recurrent acute pancreatitis
}

Xiaoyao Li ${ }^{1}$, Qi Yang ${ }^{1 *}$, Xiaolei Shi ${ }^{1}$, Weiwei Chen ${ }^{1,2}, \mathrm{Na} \mathrm{Pu}^{1}$, Weiqin $\mathrm{Li}^{1^{*}}$ and Jieshou $\mathrm{Li}^{1}$

\begin{abstract}
Background: Variants in the lipoprotein lipase (LPL), apolipoprotein C-II (APOC2), apolipoprotein A-V (APOA5), GPIHBP1 and LMF1 genes may cause severe hypertriglyceridemia (HTG), which is now the second-leading aetiology of acute pancreatitis in China.

Methods: The patient and his family were assessed for gene variants by Sanger sequencing of exons and exon-intron junctions of the LPL, GPIHBP1, APOA5, APOC2, and LMF1 genes. Post-heparin blood was collected for LPL mass and activity detection.

Results: The patient had suffered from long-term severe hypertriglyceridemia and recurrent abdominal pain for over 30 years, since age 26 , and 3 bouts of acute pancreatitis. Two heterozygous LPL single-nucleotide polymorphisms (SNPs) were compound but dislinked: a single-nucleotide substitution (c.42G $>$ A) resulting in the substitution of tryptophan with a stop codon (p.W14X) in one allele, and a single-nucleotide substitution (c.835C > G) resulting in a leucine-to-valine substitution (p.L279 V) in another allele. Only one SNP, p.L279 V, was detected in his son. Post-heparin LPL activity and mass were also lower in the patient.
\end{abstract}

Conclusion: Two heterozygous LPL SNPs, W14X and L279 V, were newly found to be compound but dislinked, which may cause long-term severe hypertriglyceridemia and recurrent acute pancreatitis.

Keywords: Hypertriglyceridemia, Lipoprotein lipase, Mutation, Acute pancreatitis, LPL gene

\section{Background}

Hypertriglyceridemia (HTG), especially severe hypertriglyceridemia (sHTG, serum triglycerides more than $11.3 \mathrm{mmol} / \mathrm{L}$ ), may cause hepatosplenomegaly, stomach ache, lipaemia retinalis, and eruptive xanthomas and is a high-risk factor for recurrent acute pancreatitis (AP) [14]. HTG can be divided into primary and secondary HTG by its aetiology. [5] Primary HTG is mainly caused by genetic loss of function, including of lipoprotein lipase (LPL), which catabolizes triglycerides (TG) in

\footnotetext{
*Correspondence: yangqi_nj@163.com; njzy_pancrea@163.com

'Surgical Intensive Care Unit (SICU), Department of General Surgery, Jinling

Hospital, Medical School of Nanjing University, Nanjing, China

Full list of author information is available at the end of the article
}

non-hepatic tissues [6, 7]; apolipoprotein C-II (APOC2), which acts as an essential LPL activator; apolipoprotein A-V (APOA5), which stabilizes the lipoproteinLPL complex; lipase maturation factor 1 (LMF1), which modulates the folding and expression of LPL; or glycosylphosphatidylinositol-anchored high-density lipoprotein-binding protein 1 (GPIHBP1), which mediates the transmembrane transport of LPL and binding between lipoprotein and LPL [8, 9]. Secondary HTG is caused by obesity, poorly controlled diabetes, excessive alcohol consumption, hypothyroidism, nonalcoholic fatty-liver disorder, renal failure, pregnancy, nephrotic syndrome, drugs or rare metabolic disorders $[8,10,11]$. Gene

(C) The Author(s). 2018 Open Access This article is distributed under the terms of the Creative Commons Attribution 4.0 International License (http://creativecommons.org/licenses/by/4.0/), which permits unrestricted use, distribution, and 
variants of LPL are reported to be the most usual cause of primary sHTG [12].

LPL belongs to the same lipase superfamily that includes hepatic lipase (HL), endothelial lipase (EL) and pancreatic lipase [13]. As a homodimeric glycoprotein, LPL is mainly synthesized in the parenchymal cells of the heart, skeletal muscle and adipose tissues. Once secreted, it is transported across the luminal surface and anchors to the vascular endothelial cells by heparan sulphate proteoglycans, where it hydrolyses triglyceride in chylomicrons (CM) and very low-density lipoproteins (VLDL) [9]. The LPL gene is encoded by 10 exons, spans approximately $30 \mathrm{~kb}$ on chromosome 8p22, and encodes a protein with 475 amino acids [9]. Genetic loss of function can be caused by gene mutations in different forms, such as insertion, duplication, deletion, nonsense mutations, frameshift mutations, and missense mutations. To date, more than 200 LPL mutations or single-nucleotide polymorphisms (SNPs) have been reported to cause severe hypertriglyceridemia syndrome and recurrent acute pancreatitis. Additionally, several heterozygous LPL SNPs are compound and cause various clinical features as severe as those caused by homozygous SNPs [14-16]. Here, we report two heterozygous LPL SNPs, W14X and L279 V, in a male Chinese patient, which were found be compound but dislinked. As dietary fat intake significantly modifies serum lipids [17], the patient's TG level has dropped significantly since changing to a completely vegan diet.

\section{Methods}

\section{Subjects}

The proband was a 61-year-old Chinese male attending Jinling Hospital in May 2017 to check his recovery from previous acute pancreatitis. He had long-term severe hypertriglyceridemia, recurrent abdominal pain for over 30 years, and 3 bouts of recurrent acute pancreatitis. Since he was 21 years old (1977), he had suffered recurrent abdominal pain with no obvious basis. Since the age of 26 (1982), his serum triglyceride level had been markedly elevated to a level that could be defined as severe hypertriglyceridemia (>11.3 mmol/L) [18]. In 2010, when he was 54 years old, type II diabetes was diagnosed, and he has taken metformin ever since. Meanwhile, he has had 3 bouts of recurrent acute pancreatitis, when he was 29 (1985), 55 (2011) and 60 years old (2016).

The first attack of acute pancreatitis, in 1985, was diagnosed as involving partial pancreatic necrosis and was treated by laparotomy. His second and third acute pancreatitis episodes happened in 2011 and 2016, respectively, and were conservatively treated by fasting, inhibition of enzymes, treatment for infection, and nutrition therapy.
The patient has followed a low-fat, high-protein, high-carbohydrate diet since 1985. After the DM diagnosis, he changed to a low-fat, low-carbohydrate, and high-protein diet. He even changed to a vegan diet in Nov. 2017. He had no drinking or smoking history and a low BMI of 16.8, and has taken fenofibrate regularly since 2015; however, recurrent abdominal pain was still occurring with no obvious cause.

Here, we sequenced the LPL, APOC2, APOA5, LMF1 and GPIHBP1 genes in the proband, his son and his wife. This study was approved by the Ethics Committee of Jinling Hospital, and signed informed consent was obtained from all subjects.

\section{Serum lipid profile analysis}

After obtaining informed written consent for the clinical and genetic study, blood samples were taken from the patient after fasting for $12 \mathrm{~h}$. Serum TG, total cholesterol (TC), high-density lipoprotein (HDL), and low-density lipoprotein (LDL) were measured enzymatically on an automatic analyser (Hitachi High-Tech, 7600-120, Japan). Serum lipoproteins, including apolipoprotein A (APO-A) and apolipoprotein B (APO-B), were measured by immunoturbidimetric assays on an automatic analyser (Hitachi High-Tech, 7600-120, Japan).

\section{Measurement of post-heparin LPL mass and activity}

Blood samples were collected into Na-EDTA tubes $10 \mathrm{~min}$ after an intravenous heparin (60 IU/kg body weight) injection. Plasma LPL protein mass concentration was determined by immunoassay using a Human LPL Elisa kit (TSZ Biological Trade, USA). Values based on a standard curve were acquired in parallel assays. LPL activity in the post-heparin plasma was determined using an LPL activity assay kit (MAK109, SIGMA, USA).

\section{Polymerase chain reaction (PCR) amplification and DNA sequencing of candidate genes}

Genomic DNA was extracted from the peripheral blood cells using a Gentra Puregene Blood kit (Qiagen, Dusseldorf, Germany) according to the manufacturer's instructions. Candidate genes involved in serum TG metabolism, including LPL, APOA5, APOC2, LMF1 and GPIHBP1, were amplified by PCR using primer sequences. Individual exons with flanking intron sequences of five genes were amplified. The PCR products were sequenced by Sanger sequencing. One nonsense change and one missense change were identified in the LPL gene. The variants were confirmed by repeated sequencing (3 times) to verify the results.

\section{Species examination}

We examined the evolutionary conservation of the W14 and L279 amino acids across various species, from 
chimpanzee (a close evolutionary relative) to mallard and zebra fish (both distant evolutionary relatives).

\section{Results}

\section{Serum lipid and lipoproteins}

The proband had long-term hypertriglyceridemia and had several fasting serum TG measurements on record since 1982. After first checking his recovery in our center in May 2017, we measured his fasting blood glucose (Glu) and 6 lipoproteins, including TG, TC, HDL, LDL, APO-A and APO-B, every month. In 1982, when first diagnosed with HTG, his TG was $11.9 \mathrm{mmol} /$ $\mathrm{L}(1054.7 \mathrm{mg} / \mathrm{dL})$. In 1985 , at the first onset of acute pancreatitis, his TG was $33.8 \mathrm{mmol} / \mathrm{L}(2992.8 \mathrm{mg} / \mathrm{dL})$. In 1988, 1989, 1991 and 1993, the proband had fasting TG of $25.3 \mathrm{mmol} / \mathrm{L}(2243.3 \mathrm{mg} / \mathrm{dL}), 18.3 \mathrm{mmol} / \mathrm{L}$ (1624 mg/dL), $16.7 \mathrm{mmol} / \mathrm{L} \quad(1478.8 \mathrm{mg} / \mathrm{dL})$, and $18.9 \mathrm{mmol} / \mathrm{L}(1673.5 \mathrm{mg} / \mathrm{dL})$, respectively, which indicated long-term severe hypertriglyceridemia. The patient used no medicine or other treatment and continued his low-fat, high-carbohydrate, and high-protein diet.

In 2010, the proband was diagnosed with type II diabetes mellitus (DM) and changed his diet to low fat, low carbohydrate, and high protein. However, still he had HTG and another attack of acute pancreatitis in 2011, with a high fasting TG level of $38.6 \mathrm{mmol} / \mathrm{L}$ ( $3417.8 \mathrm{mg} /$ $\mathrm{dL}$ ). Then, since 2015, the patient has regularly taken fenofibrate at a dosage of one pill per day, but still suffered from HTG and had a third bout of recurrent acute pancreatitis. At the onset of AP, his serum TG level was $34.16 \mathrm{mmol} / \mathrm{L}(3024.7 \mathrm{mg} / \mathrm{dL})$. After 5 days of fasting and therapy, the TG level dropped to $4.05 \mathrm{mmol} / \mathrm{L}$ (358.6 mg/dL).

Recently, in May 2017, the patient came to our center, the largest AP transfer and therapy center in China, to check his recovery from acute pancreatitis. We measured his fasting serum Glu, TG, TC, HDL, LDL, APO-A, and APO-B monthly. In May, July, August, and September 2017, the patient still suffered HTG, with fasting TG levels, respectively, of $10.75 \mathrm{mmol} / \mathrm{L}$ (951.9 mg/dL), $7.08 \mathrm{mmol} / \mathrm{L}$ (626.9 mg/dL), $7.26 \mathrm{mmol} /$ $\mathrm{L}(642.8 \mathrm{mg} / \mathrm{dL})$, and $13.17 \mathrm{mmol} / \mathrm{L}(1166.1 \mathrm{mg} / \mathrm{dL})$. After the TG measurement of $13.17 \mathrm{mmol} / \mathrm{L}$ in September 2017, the patient changed to a completely vegan diet. At his last update, the patient had a remarkable and consistent reduction in TG and even could be defined as having moderate hypertriglyceridemia [18]. In November and December 2017 and February 2018, his fasting serum TG levels, respectively, were $4.81 \mathrm{mmol} / \mathrm{L}$ (425.9 $\mathrm{mg} / \mathrm{dL}), \quad 5.25 \mathrm{mmol} / \mathrm{L}$ (464.9 $\mathrm{mg} / \mathrm{dL})$, and $4.25 \mathrm{mmol} / \mathrm{L}(376.3 \mathrm{mg} / \mathrm{dL})$. The significant drop in the TG also reduces his risk of AP, as the multivariable adjusted HR for acute pancreatitis was 1.17 per $1 \mathrm{mmol} / \mathrm{L}$ higher triglycerides in one study [19], and he has not had
AP for approximately 2 years. In the nine-month follow-up detection period, although the TG fluctuated from 13.17 to $4.25 \mathrm{mmol} / \mathrm{L}$, the other 5 lipoproteins were consistently in the normal ranges. The detailed TG level and the disease time point of the proband are shown in Fig. 1, and the follow-up measurement of Glu and 6 lipoproteins are shown in Table 1.

His son and wife had normal serum TG, $1.3 \mathrm{mmol} / \mathrm{L}$ and $0.7 \mathrm{mmol} / \mathrm{L}$, respectively. They are aged 35 and 60 years now.

\section{Genetic and biochemical analysis}

Two heterozygous SNPs in the LPL gene were identified in the proband, a single-nucleotide substitution (c.42G > A) resulting in the substitution of $14 \operatorname{Trp}$ (TGG) with a stop codon (TGA) (p.W14X) in exon 1, and a nucleotide substitution (c.835C $>\mathrm{G}$ ) resulting in a leucine-to-valine substitution (p.L279 V) in exon 6 (Fig. 2a-f). The two SNPs were newly found to be compound and, here, were named SNP1 (p.W14X) and SNP2 (p.L279 V). These two SNPs were more than 10,000 nucleotides from each other, which made it difficult to analyze their linkage relationship. Instead, we examined the genes of the proband's son and his wife. Only SNP2 (p.L279 V) was detected in his son, and neither in his wife. The results showed that SNP1 and SNP2 were in different alleles, which indicated these two SNPs were compound but dislinked (Fig. 3).

SNP1, p.W14X, directly caused LPL loss of function, due to the shortening of the LPL protein from 475 to 14 amino acids. SNP2, p.L279 V, which is registered as rs371282890 in NCBI's SNP database (https://www.ncbi.nlm.nih.gov/ SNP/snp_ref.cgi?rs=371282890), has been reported to be pathogenic by PANTHER, SIFT, and SNPs3D. [5] Here, we used another software program, polyphen (http://genetics.bwh.harvard.edu/pph2/), to analyze the pathogenicity score of p.L279 V. The results showed it was probably damaging, with a score of 0.995 (Fig. 2g). No mutations were found in the APOC2, APOA5, GPIHBP1 or LMF1 genes. The original Sanger sequencing results, polyphen score, and pedigree of the family are shown in (Fig. 2h) Moreover, both W14 and L279 were highly conserved across the species (Fig. 4), suggesting that the two amino acids may play important roles in LPL maturity and/or function.

\section{Post-heparin plasma LPL activity}

We analyzed LPL activity and mass in the post-heparin plasma of the patient in November 2017, when his TG was $4.81 \mathrm{mmol} / \mathrm{L}$. LPL mass was $185.7 \mathrm{U} / \mathrm{L}$, considerably lower than the mean value of normal controls $(382 \mathrm{U} / \mathrm{L}$, $n=10)$. LPL activity was $7.7 \mathrm{nmol} / \mathrm{mL}$, which was significantly lower than the mean value of normal controls $(19.3 \mathrm{nmol} / \mathrm{mL}, n=10)$. LPL mass was $282.7 \mathrm{U} / \mathrm{L}$ and LPL activity was $16.8 \mathrm{nmol} / \mathrm{mL}$ in his son, while LPL mass was $380.6 \mathrm{U} / \mathrm{L}$ and LPL activity was $18.8 \mathrm{nmol} / \mathrm{mL}$ 


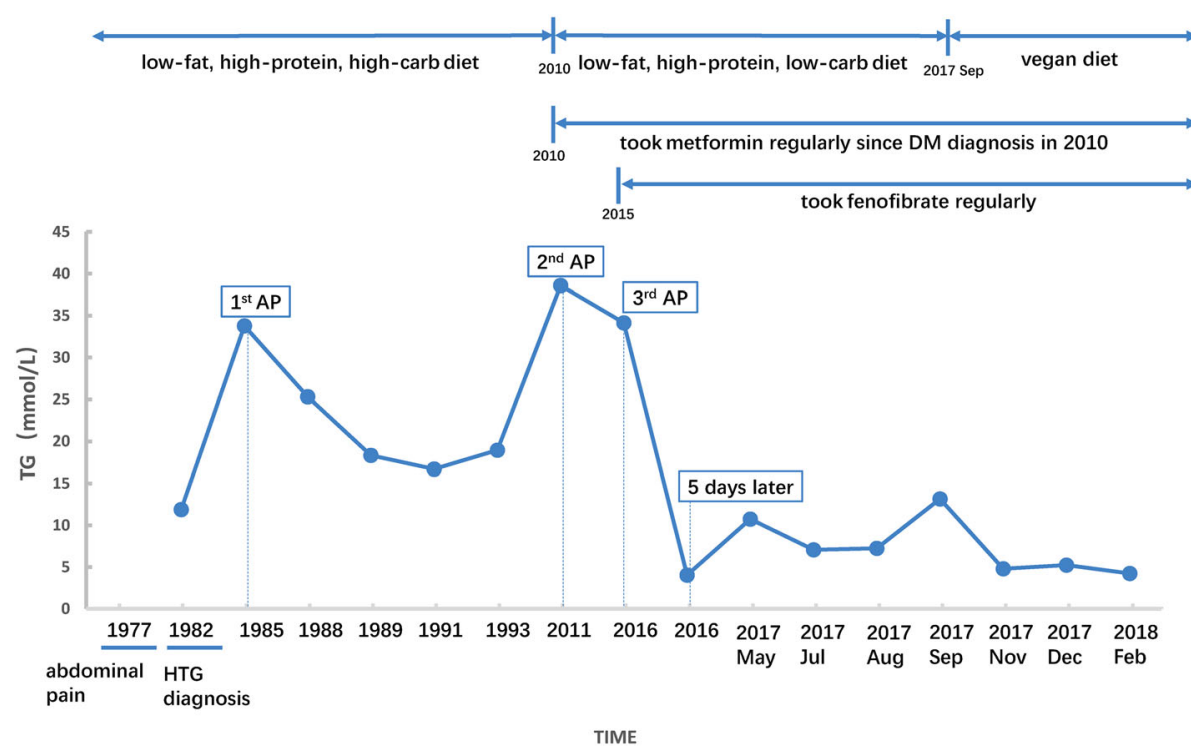

Fig. 1 Details of TG levels and disease time points of the proband TG: triglycerides; AP: acute pancreatitis

in his wife, which were both near the mean values of normal controls.

\section{Discussion}

In this study, we present a male Chinese patient who manifested long-term severe hypertriglyceridemia, recurrent abdominal pain and 3 bouts of acute pancreatitis. The sequencing results showed the proband had two heterozygous SNPs in the LPL gene, W14X and L279 V, which were newly found to be compound but dislinked. No mutations in APOA5, APOC2, LMF1 or GPIHBP1 were detected. His son was heterozygous for L279 V but had no consistent abdominal pain, HTG, acute pancreatitis, or other disease history.

LPL is the rate-limiting enzyme for the hydrolysis of the TG core of circulating TG-rich lipoproteins (CM and VLDL), which are produced by many tissues, including adipose tissue, cardiac and skeletal muscle, islets, and macrophages [20]. Deficient LPL could dramatically increase CM levels and become a high-risk factor for acute pancreatitis, hypertriglyceridemia, diabetes mellitus, and other metabolic disorders [21, 22]. The W14X SNP in LPL was first reported in a Japanese woman with hypertriglyceridemia. She had a homozygous W14X variation, resulting in nonsense-mediated decay, and her post-heparin plasma showed no LPL protein or activity. The daughters of the proband were heterozygous for this variant, but they presented with normal serum TG and normal LPL protein levels and activity in post-heparin plasma [23].

The other SNP, L279 V, has been frequently reported and well-studied. The first case report of L279 V was a heterozygous Hong Kong Chinese patient reported by Chan $\mathrm{L}$ et al [11]. Then, some population studies reported that the frequency of L279 V varied from 1/160 to 5/101 in Asian countries, such as Thailand, Mainland China, Taiwan and Hong Kong [5, 11, 12, 24-27]. But in European continental ancestry groups, L279 V has never been reported, which may suggest that genetic variations in LPL differ between different races and ethnic backgrounds. L279 V is a disease-causing missense change with LPL deficiency only among Asian patients, probably

Table 1 Lipid laboratory profiles of the proband at different follow-up times

\begin{tabular}{|c|c|c|c|c|c|c|c|}
\hline & $\mathrm{TG}(\mathrm{mmol} / \mathrm{L})$ & $\mathrm{TC}(\mathrm{mmol} / \mathrm{L})$ & $\mathrm{HDL}(\mathrm{mmol} / \mathrm{L})$ & LDL (mmol/L) & APO-A (g/L) & APO-B (g/L) & Glu (mmol/L) \\
\hline 2017 May & 10.75 & 5.93 & 1.02 & 0.71 & NA & NA & 5.61 \\
\hline $2017 \mathrm{Jul}$ & 7.08 & 3.99 & 0.99 & 1.37 & 1.23 & 0.66 & 6.31 \\
\hline 2017 Aug & 7.26 & 3.82 & 0.9 & 1.23 & 1.04 & 0.75 & 8.09 \\
\hline 2017 Sep & 13.17 & 4.77 & 1.36 & 1.41 & 1.09 & 0.7 & 6.89 \\
\hline 2017 Nov & 4.81 & 3.34 & 2.4 & 1.23 & 1.8 & 1.05 & 5.96 \\
\hline 2017 Dec & 5.25 & 3.75 & 0.83 & 1.33 & 1.23 & 0.71 & 6.71 \\
\hline 2018 Feb & 4.25 & 3.75 & 0.78 & 1.39 & 0.98 & 0.64 & 7.38 \\
\hline
\end{tabular}

TG triglycerides; TC total cholesterol; $H D L$ high-density lipoprotein; $L D L$ low-density lipoprotein; $A P O-A$ apo-lipoprotein $A ; A P O-B$ apo-lipoprotein B; Glu glucose 


\section{a}

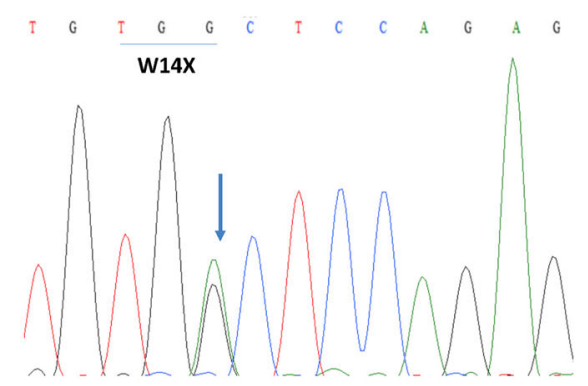

C
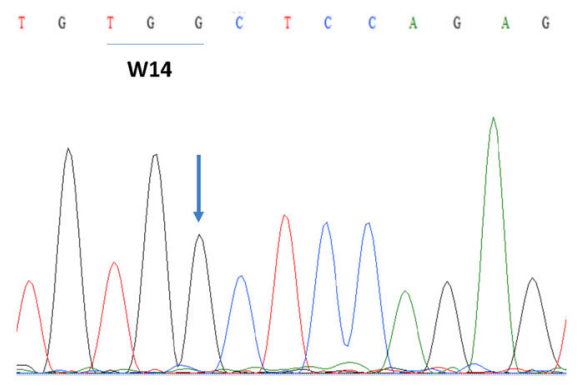

e

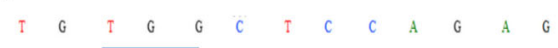

W14

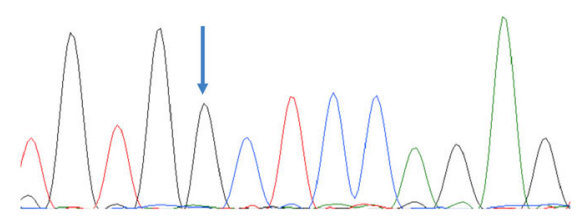

g

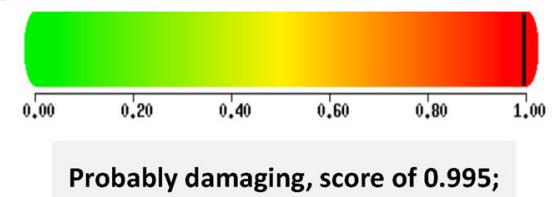

sensitivity: 0.68 ; specificity: 0.97 b

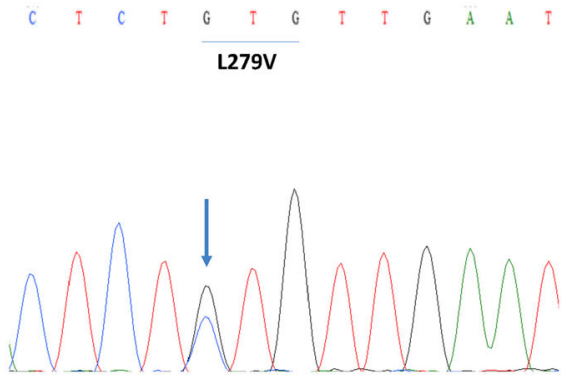

d

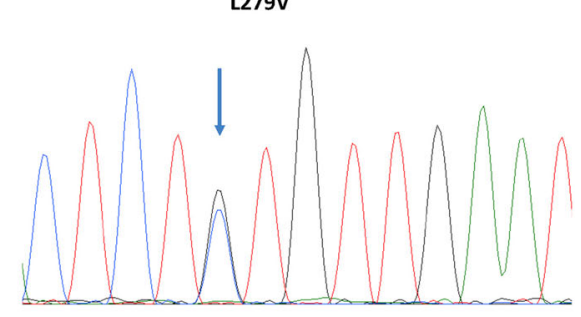

f

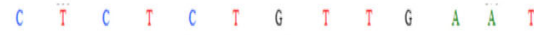

L279

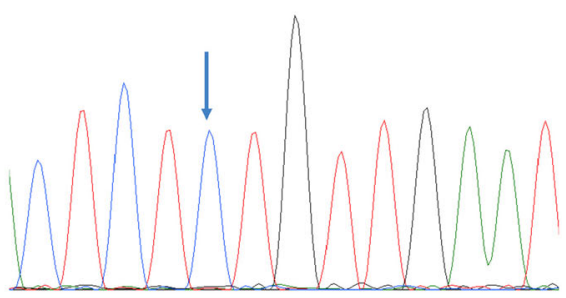

h

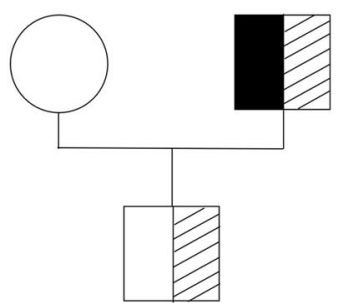

Fig. 2 Partial nucleotide sequences of the lipoprotein lipase (LPL) gene and pedigree of the family. a The proband was heterozygous for the nucleotide substitution in exon 1 that resulted in W14X. The arrow shows the nucleotide substitution from G to A. b The proband was heterozygous for the nucleotide substitution in exon 6 that resulted in L279 V. The arrow shows the nucleotide substitution from C to G. c W14X was not detected in the son of the proband. $\mathbf{d}$ The son of the proband was heterozygous for the nucleotide substitution in exon 6 , which resulted in $L 279 \mathrm{~V}$. The arrow shows the nucleotide substitution from C to G. e W14X was not detected in the wife of the proband. $\mathbf{f} L 279 \mathrm{~V}$ was not detected in the wife of the proband. $\mathbf{g}$ L279 V was predicted to be damaging by polyphen software. $\mathbf{h}$ Pedigree of the family. Black boxes represent W14X, and dashed boxes represent L279 V

because of the founder effect [5, 24]. L279 V has been verified to be pathogenic by both biomedical methods and in vitro studies, such as transfecting wild-type and L279 V LPL plasmids into COS-1 cells
$[11,27]$. However, there has been no in vivo research to analyze its particular pathogenic mechanism. L279 V, located in exon 6 of the LPL gene, acts as a heparin binding site using two structurally 


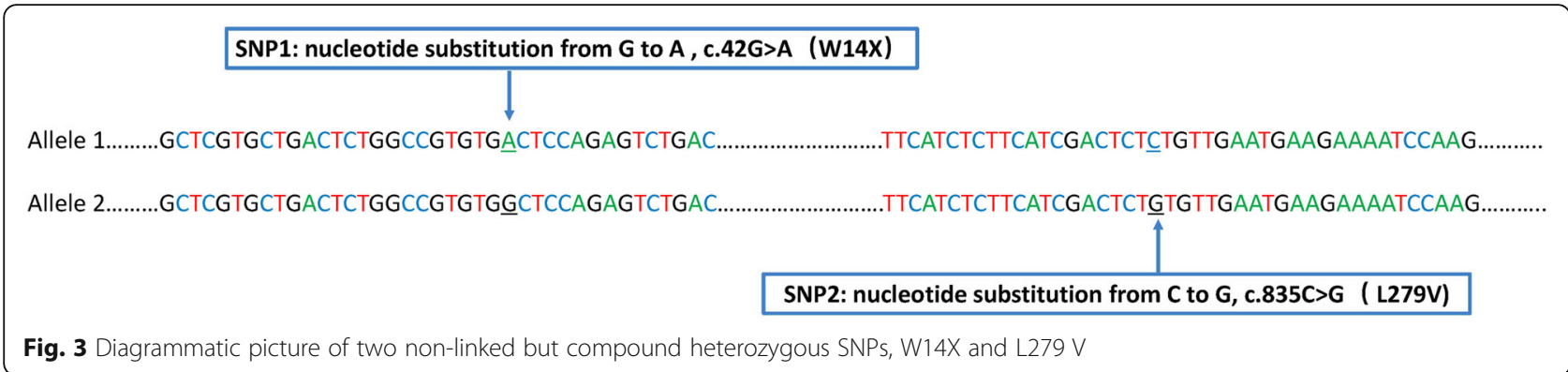

relevant disulphide bridges (Cys278-Cys283 and Cys264-Cys275). Leucine 279 may play a significant role in the catalytic function of LPL by constituting one of the two disulphide bridges (Cys278-Cys283), which are important for the catalytic function of heparin binding [12, 27].

Furthermore, we assessed the W14 and L279 residues by multiple-species sequence alignment. The results showed that W14 and L279 were both highly conserved throughout evolution, from chimpanzee to torafugu and zebra fish, suggesting their important roles in LPL function.

Ageing, obesity, diet, drugs, hyperinsulinaemia, exercise and other factors may promote clinical manifestations of LPL-gene heterozygous defects [23]. Goni et al. found that a low-fat diet improved the lipid profile of MTNR1B rs10830963 genetic variants, indicating the significance of personalized dietary interventions in improving lipid metabolism caused by genetic variation [17]. Our male Chinese patient has been taking fenofibrate regularly since 2015, but his serum TG was still above $7 \mathrm{mmol} / \mathrm{L}$. However, since he changed to a vegan diet in November 2017, his TG decreased to approximately $5 \mathrm{mmol} / \mathrm{L}$, without any changes in drug use or exercise frequency. His 35-year-old son, with one heterozygous SNP (L279 V), has been maintaining a healthy lifestyle including a low-fat diet and high exercise frequency and intensity, which may help him to maintain normal levels of TG and LPL activity [28].

The genetic basis of most severe hypertriglyceridemia and recurrent pancreatitis patients is still unknown and remain a subject of further investigations. In future research, we aim to detect the rates of the W14X and L279 V mutations in a large Chinese population and verify the pathogenic mechanisms of these two SNPs in vivo.

\section{Conclusion}

Here, we present a typical male Chinese patient with long-term hypertriglyceridemia, recurrent abdominal pain, and recurrent pancreatitis. By Sanger sequencing of the LPL, APOA5, APOC2, LMF1, and GPIHBP1 genes, two LPL SNPs, W14X and L279 V, were newly found to be compound but dislinked in the proband. The proband's son had one SNP, L279 V, and normal TG, which may be due to his healthy lifestyle including a low-fat diet and high intensity and frequency of exercise. Therefore, we propose that it is important for HTG patients to have both early-phase gene detection and a healthy lifestyle.

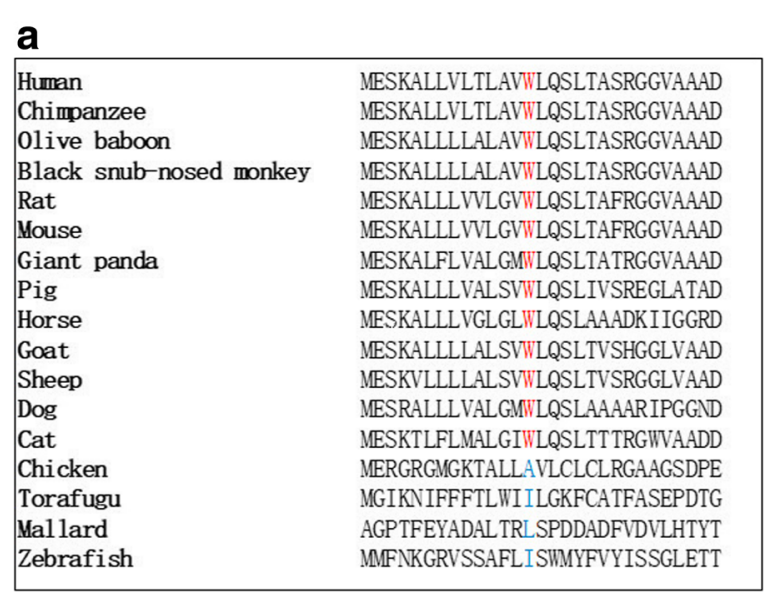

\begin{tabular}{|c|c|}
\hline Human & LVKCSHERSIHLFIDSLLNEENPSKAYRCSSKEAF \\
\hline Chimpanzee & LVKCSHERSIHLFIDSLLNEENPSKAYRCSSKEAF \\
\hline 0live baboon & LVKCSHERSIHLFIDSLLNEENPSKAYRCSSKEAF \\
\hline Black snub-nosed monkey & LVKCSHERSIHLFIDSLLNEENPSKAYRCSSKEAF \\
\hline Rat & LVKCSHERSIHLFIDSLLNEENPSKAYRCNSKEAF \\
\hline Mouse & LVKCSHERSIHLFIDSLLNEENPSKAYRCNSKEAF \\
\hline Giant panda & LVKCSHERSIHLFIDSLLNEENPSKAYRCNSKEAF \\
\hline Pig & LVKCSHERSIHLFIDSLLNEENPSKAYRCNSKEAF \\
\hline Horse & LVKCSHERSIHLFIDSLLNEENPSKAYRCNSKEAF \\
\hline Goat & LVKCSHERSVHLFIDSLLNEENPSKAYRCNSKEAF \\
\hline Sheep & LVKCSHERSVHLFIDSLLNEENPSKAYRCNSKEAF \\
\hline Dog & LVKCSHERSIHLFIDSLLNEENPSKAYRCNSKEAF \\
\hline Cat & LVKCSHERSIHLFIDSLLNEENPSKAYRCNSKEAF \\
\hline Chicken & LVKCSHERSIHLFIDSLLYEEKPSMAYRCNTKEAF \\
\hline Torafugu & LVKCSHERSIHLFIDSLINTEQQSVAYRCNSKEAF \\
\hline Mallard & LVKCSHERSIHLFIDSLLYEEKPSMAYRCNTKEAF \\
\hline Zebrafish & IVKCSHERSIHLFIDSL VNQDHESMAFRCSSRDSF \\
\hline
\end{tabular}

Fig. 4 Evolutionary conservation of the W14 (a) and L279 (b) amino acid residues in various species 


\section{Abbreviations}

AP: Acute pancreatitis; APO-A: Apo-protein A; APOA5: Apolipoprotein A-V; APOB: Apo-protein B; APOC2: Apolipoprotein C-II; BMI: Body mass index; Carb: Carbohydrate; CM: Chylomicron; DM: Diabetes mellitus; EL: Endothelial lipase; Glu: Glucose; GPIHBP1: Glycosylphosphatidylinositol-anchored high-density lipoprotein binding protein 1; HDL: High density lipoprotein; HL: Hepatic lipase; HTG: Hypertriglyceridemia; LDL: Low density lipoprotein; LMF1: Lipase maturation factor 1; LPL: Lipoprotein lipase; PCR: Polymerase chain reaction; sHTG: Severe hypertriglyceridemia; SNP: Single nucleotide polymorphism; SNP1: p.W14X; SNP2: p.L279 V; TC: Total cholesterol; TG: Triglyceridemia

\section{Acknowledgements}

The authors are indebted to all doctors and researchers for the follow-up assessment and data collection during the study from the severe acute pancreatitis care center of Jinling Hospital, Medical School of Nanjing University.

\section{Funding}

This study was funded by National Natural Science Foundation of China,(No.81570584), Social development project of Jiangsu Province(BE2015685)and Medical Research Funding of PLA(AWS14C003).

\section{Availability of data and materials}

Data for the analyses are available from the corresponding author on request.

\section{Authors' contributions}

All authors contributed extensively to the work presented in this paper. Study concept and design: LXY, YQ. Statistical analysis: CWW,PN. Drafting of the manuscript: LXY, SXL. Critical revision of the manuscript for important intellectual content: LWQ. Administrative, technical, or material support: YQ. Study supervision: LWQ \& LJS. All authors have read and approved the final version of this manuscript

\section{Ethics approval and consent to participate}

The study was approved by the ethics committee of the Jinling Hospital, Medical School of Nanjing University. All participants consented to participate the study and the written informed consent was obtained from each subject.

\section{Competing interests}

The authors declare that they have no competing interests.

\section{Publisher's Note}

Springer Nature remains neutral with regard to jurisdictional claims in published maps and institutional affiliations.

\section{Author details}

${ }^{1}$ Surgical Intensive Care Unit (SICU), Department of General Surgery, Jinling Hospital, Medical School of Nanjing University, Nanjing, China. ${ }^{2}$ Department of Gastroenterology, Clinical Medical College, Yangzhou University, Yangzhou, Jiangsu, China.

Received: 10 March 2018 Accepted: 28 May 2018

Published online: 19 June 2018

\section{References}

1. Rouis M, Lohse P, Dugi KA, Lohse P, Beg OU, Ronan R, Talley GD, Brunzell $J$ D, Santamarina-Fojo S. Homozygosity for two point mutations in the lipoprotein lipase (LPL) gene in a patient with familial LPL deficiency: LPL(Asp9->Asn, Tyr262->His). J Lipid Res. 1996;37:651-61.

2. Jacobson TA, Ito MK, Maki KC, Orringer CE, Bays HE, Jones PH, McKenney JM, Grundy SM, Gill EA, Wild RA, et al. National Lipid Association recommendations for patient-centered management of dyslipidemia: part 1 - executive summary. J Clin Lipidol. 2014;8:473-88.

3. Miller M, Stone NJ, Ballantyne C, Bittner V, Criqui MH, Ginsberg HN, Goldberg AC, Howard WJ, Jacobson MS, Kris-Etherton PM, et al. Triglycerides and cardiovascular disease: a scientific statement from the American Heart Association. Circulation. 2011;123:2292-333.

4. Jiang J, Wang Y, Ling Y, Kayoumu A, Liu G, Gao X. A novel APOC2 gene mutation identified in a Chinese patient with severe hypertriglyceridemia and recurrent pancreatitis. Lipids Health Dis. 2016;15:12.

5. Khovidhunkit W, Charoen S, Kiateprungvej A, Chartyingcharoen $P$, Muanpetch S, Plengpanich W. Rare and common variants in LPL and
APOA5 in Thai subjects with severe hypertriglyceridemia: a resequencing approach. J Clin Lipidol. 2016:10:505-11. e501

6. Chait A, Robertson HT, Brunzell JD. Chylomicronemia syndrome in diabetes mellitus. Diabetes Care. 1981:4:343-8.

7. Chait A, Brunzell JD. Chylomicronemia syndrome. Adv Intern Med. 1992;37:249-73.

8. Black DM, Sprecher DL. Dietary treatment and growth of hyperchylomicronemic children severely restricted in dietary fat. Am J Dis Child. 1993;147:60-2.

9. Geldenhuys WJ, Lin L, Darvesh AS, Sadana P. Emerging strategies of targeting lipoprotein lipase for metabolic and cardiovascular diseases. Drug Discov Today. 2017:22:352-65.

10. Merkel M, Eckel RH, Goldberg IJ. Lipoprotein lipase: genetics, lipid uptake, and regulation. J Lipid Res. 2002;43:1997-2006.

11. Chan L, Mak Y, Tomlinson B, Baum L, Wu X, Masarei J, Pang C. Compound heterozygosity of Leu252Val and Leu252Arg causing lipoprotein lipase deficiency in a chinese patient with hypertriglyceridemia. Eur J Clin Investig. 2000;30:33-40.

12. Chen $T Z$, Xie $S L$, Jin R, Huang ZM. A novel lipoprotein lipase gene missense mutation in Chinese patients with severe hypertriglyceridemia and pancreatitis. Lipids Health Dis. 2014;13:52.

13. Hide WA, Chan L, Li WH. Structure and evolution of the lipase superfamily. J Lipid Res. 1992:33:167-78.

14. Bruin T, Tuzgol S, Mulder WJ, van den Ende AE, Jansen $H$, Hayden MR, Kastelein JJ. A compound heterozygote for lipoprotein lipase deficiency, Val69->Leu and Gly188-> Glu: correlation between in vitro LPL activity and clinical expression. J Lipid Res. 1994;35:438-45.

15. Bijvoet SM, Wiebusch H, Ma Y, Reymer PW, Bruin T, Bakker HD, Funke H, Assmann G, Hayden MR, Kastelein JJ. Compound heterozygosity for a known and a novel defect in the lipoprotein lipase gene (Asp250->Asn; Ser251->Cys) resulting in lipoprotein lipase (LPL) deficiency. Neth J Med. 1996;49:189-95.

16. Henderson HE, Hassan F, Marais D, Hayden MR. A new mutation destroying disulphide bridging in the C-terminal domain of lipoprotein lipase. Biochem Biophys Res Commun. 1996:227:189-94.

17. Goni L, Sun D, Heianza Y, Wang T, Huang T, Cuervo M, Martinez JA, Shang X, Bray GA, Sacks FM, Qi L. Macronutrient-specific effect of the MTNR1B genotype on lipid levels in response to 2 year weight-loss diets. J Lipid Res. 2018:59:155-61.

18. Berglund L, Brunzell JD, Goldberg AC, Goldberg IJ, Sacks F, Murad MH, Stalenhoef AF. Evaluation and treatment of hypertriglyceridemia: an Endocrine Society clinical practice guideline. J Clin Endocrinol Metab. 2012;97:2969-89.

19. Pedersen SB, Langsted A, Nordestgaard BG. Nonfasting mild-to-moderate hypertriglyceridemia and risk of acute pancreatitis. JAMA Intern Med. 2016; 176:1834-42.

20. Wang $\mathrm{H}$, Eckel $\mathrm{RH}$. Lipoprotein lipase: from gene to obesity. Am J Physiol Endocrinol Metab. 2009;297:E271-88.

21. Feoli-Fonseca JC, Levy E, Godard M, Lambert M. Familial lipoprotein lipase deficiency in infancy: clinical, biochemical, and molecular study. J Pediatr. 1998;133:417-23.

22. Raupp P, Keenan C, Dowman M, Nath R, Hertecant J. Lipoprotein lipase deficiency and transient diabetes mellitus in a neonate. J Inherit Metab Dis. 2002;25:413-4

23. Nakamura $T$, Suehiro $T$, Yasuoka N, Yamamoto $M$, Ito H, Yamano T, Hashimoto K. A novel nonsense mutation in exon 1 and a transition in intron 3 of the lipoprotein lipase gene. J Atheroscler Thromb. 1996:3:17-24.

24. Chan AO, But WM, Lau GT, Tse WY, Shek CC. A novel nonsense mutation in the LPL gene in a Chinese neonate with hypertriglyceridemia. Clin Chim Acta. 2006:368:120-4.

25. Xie SL, Chen TZ, Huang XL, Chen C, Jin R, Huang ZM, Zhou MT. Genetic variants associated with gestational hypertriglyceridemia and pancreatitis. PLoS One. 2015;10:e0129488.

26. Jap TS, Jenq SF, Wu YC, Chiu CY, Cheng HM. Mutations in the lipoprotein lipase gene as a cause of hypertriglyceridemia and pancreatitis in Taiwan. Pancreas. 2003:27:122-6.

27. Chan LY, Lam CW, Mak YT, Tomlinson B, Tsang MW, Baum L, Masarei JR, Pang CP. Genotype-phenotype studies of six novel LPL mutations in Chinese patients with hypertriglyceridemia. Hum Mutat. 2002;20:232-3.

28. Duncan GE, Perri MG, Theriaque DW, Hutson AD, Eckel RH, Stacpoole PW. Exercise training, without weight loss, increases insulin sensitivity and postheparin plasma lipase activity in previously sedentary adults. Diabetes Care. 2003:26:557-62. 